Check for updates

Cite this: RSC Adv., 2018, 8, 11078

Received 3rd February 2018 Accepted 1st March 2018

DOI: $10.1039 / c 8 r a 01086 b$

rsc.li/rsc-advances

\section{Synergistic effects of boron-doped silicone resin and a layered double hydroxide modified with sodium dodecyl benzenesulfonate for enhancing the flame retardancy of polycarbonate}

\author{
Yi Jiang, (D) a Zhifeng Hao, ${ }^{\text {a }}$ Hongsheng Luo, ${ }^{\text {a }}$ Zehui Shao, ${ }^{a}$ Qian $\mathrm{Yu}^{\mathrm{a}}{ }^{\mathrm{a}}$ Ming Sun, (D) \\ Yong $\mathrm{Ke}^{\mathrm{b}}$ and Yilong Chen ${ }^{\mathrm{b}}$
}

To improve the flame retardancy of polycarbonate (PC), a novel and environmentally friendly flame retardant was synthesized by combining boron-doped silicone resin (BSR) with a layered double hydroxide (LDH) modified with sodium dodecyl benzenesulfonate (SDBS) which was denoted as DBSLDH/BSR. The structure of the hybrid was characterized by Fourier transform infrared (FTIR) spectroscopy and X-ray photoelectron spectroscopy (XPS), which indicated that BSR was successfully combined with DBS-LDH. X-ray diffraction (XRD) studies showed that the reaction of BSR occurred only on the surface of DBS-LDH. In addition, scanning electron microscopy (SEM) was used to further verify the combination of DBS-LDH with BSR. PC exhibited the optimum flame retardancy following the incorporation of $10 \mathrm{wt} \%$ DBS-LDH/BSR ( 5 wt\% DBS-LDH and 5 wt\% BSR). Based on thermogravimetric analysis, the char residue of this PC composite in air at $750{ }^{\circ} \mathrm{C}$ increased to $3.60 \mathrm{wt} \%$. Mechanical test showed that the DBS-LDH/BSR could affect the mechanical properties after incorporation into PC. According to the UL-94 vertical burning test, the flame retardant rating of the PC composite improved to $\mathrm{V}-\mathrm{O}$. Furthermore, the limiting oxygen index (LOI) value of the PC composite increased to $34 \%$. According to the cone calorimeter test, the peak heat release rate (PHRR) dramatically decreased by $44 \%$. The morphology of the PC composite after combustion was characterized by SEM, which revealed that the pores of the composite were smaller than those of pure PC. This result was attributed to the limited spread of oxygen and heat permeation. Thus, both DBS-LDH and BSR contributed to the synergistic effects of reducing the fire hazard of PC.

\section{Introduction}

Polycarbonate (PC), a tough thermoplastic resin with carbonate groups, has been widely used in many fields, including glass assembly and the automotive and electronics industries. ${ }^{\mathbf{1 , 2}}$ However, due to its high flammability and the production of large amounts of smoke and toxic gases during combustion, which is accompanied by severe dripping, researchers have improved the flame retardancy of this material. ${ }^{3-5}$

Recently, it has made some progress in the fire safety of PC. ${ }^{6}$ For example, halogen flame retardants form some of the most widely applied flame retardant materials, but they do have clear disadvantages: generation of toxic and corrosive gases during combustion. $^{7}$ Therefore, non-halogen flame retardants ${ }^{\mathbf{8 - 1 0}}$ have been paid more attention today. Some environmental flame

${ }^{a}$ School of Chemical Engineering and Light Industry, Guangdong University of Technology, Guangzhou 510006, P. R. China.E-mail: haozhifeng3377@163.com

${ }^{b}$ Heyuan Jingwang Electronic Technology (Longchuan) Co., Ltd, Heyuan 517300, P. R. China retardants based on phosphorus, nitrogen, silicon, boron and other elements have gradually substituted halogen flame retardants. Even though the flame retardancy of PC has dramatically improved, one type flame retardant may affect other properties of the material, such as the mechanical properties, dispersion and thermal stability. Greater flame-retardant loadings are frequently added in polymers to improve flame retardancy, but this approach is detrimental to the intrinsic properties of the polymers. To improve the flame retardancy of PC, we examined the synergistic effects of two types of flame retardants.

Layered double hydroxides (LDHs) have shown to offer good flame retardancy because of their unique chemical composition. These are potentially eco-friendly flame retardants for improving the fire-retardant properties of polymers. ${ }^{\mathbf{1 1 , 1 2}}$ The flame retardant mechanism of LDHs can be attributed to the combination of the following three functions: (1) heat absorption, (2) gas dilution, and (3) char formation. The high polarity of these materials greatly affects their dispersion in the polymer matrix. Additionally, to achieve the desired flame retardancy, high LDH loadings 
are necessary. Thus, researchers have applied organic anions to modify LDHs, such as fatty acid salts, ${ }^{13}$ sulfonates ${ }^{14}$ and phosphates ${ }^{15}$ which improves the dispersion of LDHs in polymers. ${ }^{16-18}$ In addition, some synergistic effects of LDHs with other fire retardants have become the focus in the field of flame retardant technology. For example, ammonium polyphosphate, ${ }^{19}$ red phosphorus, ${ }^{20}$ zinc borate,${ }^{21}$ graphene oxide,${ }^{22}$ and intumescent flame retardant (IFR) ${ }^{23}$ play roles as synergists to improve the flame retardancy of polymers. It is reported that interlayer gallery distance of LDHs can be enlarged after modified with sodium dodecyl benzenesulfonate (SDBS), which enhances the compatibility of LDHs with polymer matrix. ${ }^{17}$ High contents of single inorganic flame retardants are known to affect the mechanical properties of bulk polymers. Thus, the combination of inorganic and organic flame retardants is a good strategy for maintaining the properties of polymers.

Organic silicone, ${ }^{24,25}$ as organic flame retardant, has been applied to many polymers and turns into a promising class of cost-effective, minimally toxic, drip-proof, and eco-friendly flame retardants. During combustion, the organic silicone flame retardant can transfer to the surface of the polymer, forming inorganic oxygen and heat-insulating protective layers containing $\mathrm{Si}-\mathrm{O}$ and $\mathrm{Si}-\mathrm{C}$ bonds. These layers can inhibit the release of decomposed product and protect the polymer from further burning. Furthermore, boron (B)-containing flame retardants have been reported to show good flame retardancy. ${ }^{26,27}$ They are often used as synergists in flame-retardant systems. B-containing compounds can promote the formation of char during combustion, ${ }^{28,29}$ which can inhibit the effusion of volatile combustibles and protect the char layer from further oxidation. Therefore, to obtain highly effective flame retardants, we introduce boron into pure silicone resins, marked as B-doped silicone resin (BSR). In our previous work, we found that BSR possessed better thermal stability than pure silicon resins. ${ }^{30}$ Thus, we apply BSR as a flame retardant in this study.
In this paper, we focus on the synergistic effects of combining BSR with DBS-LDH as flame retardants on PC composites. The intercalation of DBS ions in LDH increases the distance between layers, which reduces the polarity of LDH in PC. In addition, the siloxane monomers used for preparing the silicone resin can hydrolyze via hydrolysis. After that, the hydrolyzed siloxanes can dehydrate with the hydroxyls of boric acid, hence B element can combine with these siloxanes. Subsequently, we can prepare BSR through polycondensation. Furthermore, BSR with hydroxyls can dehydrate with the hydroxyls of DBS-LDH (Scheme 1). The combination of organic BSR with DBS-LDH can improve the compatibility of inorganic particles in PC. Therefore, the newly synthetic DBS-LDH/BSR is anticipated to reduce the fire hazard of the PC composites.

\section{Experiment}

\subsection{Materials}

Magnesium nitrate hexahydrate $\left(\mathrm{Mg}\left(\mathrm{NO}_{3}\right)_{2} \cdot 6 \mathrm{H}_{2} \mathrm{O}\right)$, aluminium nitrate nonahydrate $\left(\mathrm{Al}\left(\mathrm{NO}_{3}\right)_{3} \cdot 9 \mathrm{H}_{2} \mathrm{O}\right)$, SDBS, sodium hydroxide $(\mathrm{NaOH})$, boric acid, concentrated hydrochloric acid $(\mathrm{HCl}$, $36.5 \%)$ and ethanol (99.7\%) were supplied by Tianjin Damao Chemical Reagent Factory (Tianjin, China) and were used without further purification. Diethoxydimethylsilane and phenyltriethoxysilane were provided by Suzhou Chuangjia Plastic Co., Ltd. PC was purchased from Suzhou Chuangjia Plastic Co., Ltd.

\subsection{Synthesis of DBS-LDH/BSR}

DBS-LDH was prepared using a co-precipitation method. ${ }^{31}$ SDBS solution $(0.1 \mathrm{M})$ was introduced into a $250 \mathrm{ml}$ three-neck round flask that was equipped with constant pressure liquid funnels, reflux-condenser and $\mathrm{pH}$ meter and a magnetic stirrer. A mixture solution containing $\mathrm{Mg}\left(\mathrm{NO}_{3}\right)_{2} \cdot 6 \mathrm{H}_{2} \mathrm{O}(0.13 \mathrm{M})$ and $\mathrm{Al}\left(\mathrm{NO}_{3}\right)_{3} \cdot 9 \mathrm{H}_{2} \mathrm{O}(0.06 \mathrm{M})$ was then slowly added to the above
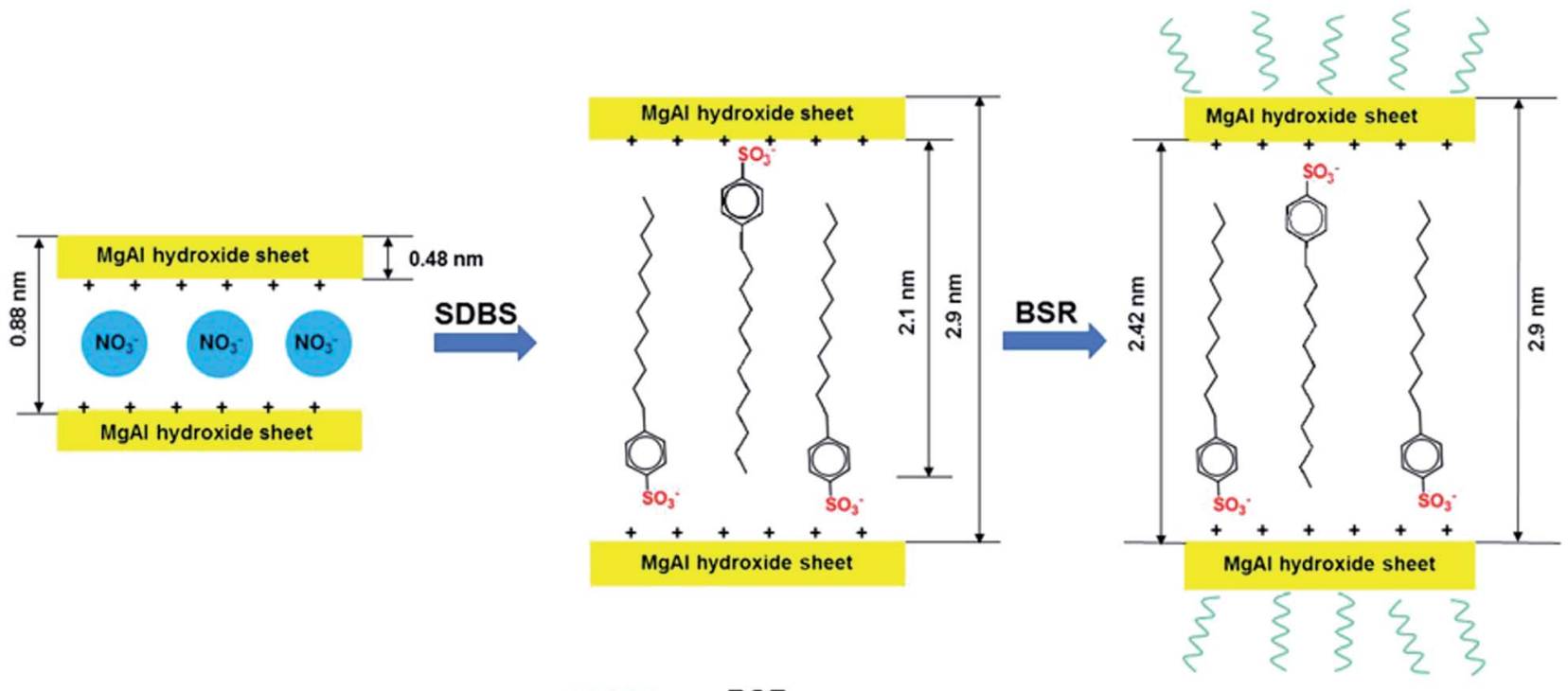

W BSR

Scheme 1 Schematic illustration of the synthetic route to DBS-LDH/BSR. 
flask with vigorous stirring at a constant $\mathrm{pH}=10.0 \pm 0.5$, adjusted by the synchronous dropwise addition of $1 \mathrm{M} \mathrm{NaOH}$ solution. During the reaction, the resultant slurry was continuously stirred for $30 \mathrm{~min}$ at $50{ }^{\circ} \mathrm{C}$. Subsequently, we aged the slurry for $24 \mathrm{~h}$ at a temperature of $70{ }^{\circ} \mathrm{C}$. Finally, the white product was filtered and washed thoroughly with distilled water until the $\mathrm{pH}$ of the solution was about 7, and then dried in a freeze dryer for $24 \mathrm{~h}$, which was marked as DBS-LDH.

BSR was synthesized using a hydrolysis-polycondensation method..$^{30}$ Diethoxydimethylsilane (6.34 g), phenyltriethoxysilane $(24.0 \mathrm{~g}), 40 \mathrm{ml}$ absolute alcohol, and $1.73 \mathrm{~g}$ boric acid were added into a $250 \mathrm{ml}$ four-necked which was equipped with a magnetic stirrer, a water condenser, and a constant pressure liquid funnel. The resulting mixture was vigorously stirred. At the temperature of $65{ }^{\circ} \mathrm{C}, 3.5 \mathrm{ml}$ deionized water and $0.9 \mathrm{ml}$ hydrochloric acid $(1 \mathrm{M})$ were added into the above flask dropwise. Then the mixture was kept refluxing for $2 \mathrm{~h}$, obtaining the hydrolysate. Subsequently, the hydrolysate was heated to $135{ }^{\circ} \mathrm{C}$ under vacuum $(0.06 \mathrm{MPa})$ to remove the ethanol and other small molecules. Finally, the resulting product was transparent viscous liquid and recorded as BSR.

Here was the typical procedure to combine DBS-LDH with BSR. BSR ( $6 \mathrm{~g}$ ) was first added into an aqueous alcohol solution containing $200 \mathrm{ml}$ of alcohol and $20 \mathrm{ml}$ of water under stirring for $30 \mathrm{~min}$. After that, $6 \mathrm{~g}$ of DBS-LDH was added, following with stirring the mixture for $3 \mathrm{~h}$. The $\mathrm{pH}$ of the system was adjusted to 9-10 with sodium hydroxide. And the reaction continued for another 24 h. Finally, the resulting product was filtered and thoroughly washed with deionized water until the pH was 7 . Finally, the product was dried in a freeze dryer for $24 \mathrm{~h}$, and was marked as DBS-LDH/BSR.

\subsection{Preparation of PC/DBS-LDH/BSR}

PC and its composites were prepared by adding different contents of flame retardants (DBS-LDH, BSR or DBS-LDH/BSR), and the components are listed in Table 1. Briefly, PC composite with $10 \mathrm{wt} \%$ DBS-LDH was prepared as follows: $90 \mathrm{wt} \% \mathrm{PC}$ and $10 \mathrm{wt} \%$ DBS-LDH were mixed in a co-rotating twin-screw extruder with a screw temperature profile of $180,178,178$, 178,178 , and $183{ }^{\circ} \mathrm{C}$ from the hopper to the die. The resulting mixture was injected and moulded into various sheets with a temperature profile of 215,215 , and $215^{\circ} \mathrm{C}$ from the hopper to the nozzle. PC/BSR10 and PC/DBS-LDH/BRS composites were prepared using the same method.

Table 1 Components of the PC-based composite samples

\begin{tabular}{llll}
\hline & \multicolumn{2}{l}{ Component (wt\%) } \\
\cline { 2 - 4 } Sample & PC & DBS-LDH & BSR \\
\hline PC & 100 & 0 & 0 \\
PC/DBS-LDH10 & 90 & 10 & 0 \\
PC/BSR10 & 90 & 0 & 10 \\
PC/DBS-LDH7/BSR3 & 90 & 7 & 3 \\
PC/DBS-LDH5/BSR5 & 90 & 5 & 5
\end{tabular}

\subsection{Characterization}

Fourier transform infrared (FTIR) spectroscopy was used to identify the chemical structures of the prepared samples, and the spectra were recorded on a Thermo Scientific Nicolet 6700 FTIR spectrometer.

X-ray diffraction (XRD) patterns of the prepared samples were recorded with an XPERT-PRO X-ray diffractometer. The $\mathrm{Cu}$ $\mathrm{K} \alpha(\lambda=0.1542 \mathrm{~nm})$ radiation source was operated at $40 \mathrm{kV}$ and $30 \mathrm{~mA}$ with a scan rate of $2^{\circ} \mathrm{min}^{-1}$ from $2.5^{\circ}$ to $30^{\circ}$.

$\mathrm{X}$-ray photoelectron spectroscopy (XPS) measurements were performed on a Kratos AXIS His spectrometer using a monochromatized Al K $\alpha$ X-ray source (1486.6 eV photons).

Thermal stabilities of the flame retardants, pure PC and its composites were studied by thermogravimetric analysis (TGA) (NETZSCH), which was performed with a heating rate of $10{ }^{\circ} \mathrm{C} \mathrm{min}{ }^{-1}$ under air and nitrogen at a flow rate of $40 \mathrm{ml} \mathrm{min}{ }^{-1}$ from $30{ }^{\circ} \mathrm{C}$ to $800{ }^{\circ} \mathrm{C}$.

Mechanical tests were performed using an AI-7000M servo control system universal testing machine according to the ASTM D3039-08 method, at a speed of $10 \mathrm{~mm} \mathrm{~min}^{-1}$.

Limiting oxygen index (LOI) values were measured using an oxygen index instrument (Beijing Xinsheng Zhuo Rui Technology Co., Ltd, China). The samples' dimensions were $120 \times$ $10 \times 4 \mathrm{~mm}^{3}$, and the tests were performed according to standard ASTM D2863.

Vertical burning tests were performed in a burning chamber (Beijing Xinsheng Zhuo Rui Technology Co., Ltd, China) on samples with dimensions of $125 \times 13 \times 3 \mathrm{~mm}^{3}$ according to standard ASTM D3801.

Morphological features of the flame retardants, the surfaces and cross-sections of the char residues were investigated by scanning electron microscopy (SEM).

Combustion tests were performed on a cone calorimeter FTT007 (Fire Testing Technology, UK) according to ISO 5600 standard procedures with $100 \times 100 \times 3 \mathrm{~mm}^{3}$ specimens. Each specimen was exposed horizontally to a $35 \mathrm{~kW} \mathrm{~m}^{-2}$ external heat flux.

\section{Results and discussion}

\subsection{Characterization of DBS-LDH/BSR}

Fig. 1 shows the FTIR spectra of $\mathrm{NO}_{3}-\mathrm{LDH}, \mathrm{DBS}-\mathrm{LDH}, \mathrm{BSR}$ and DBS-LDH/BSR. As can be seen in the spectrum of $\mathrm{NO}_{3}-\mathrm{LDH}$, the peak at $3430 \mathrm{~cm}^{-1}$ is ascribed to the $\mathrm{O}-\mathrm{H}$ group. The absorption of $\mathrm{NO}_{3}{ }^{-}$appears at $1350 \mathrm{~cm}^{-1}$. In the spectrum of BSR, the peak at $3460 \mathrm{~cm}^{-1}$ is attributed to the stretching vibrations of $\mathrm{O}-\mathrm{H}$ groups. The absorption bands at $2965-2870 \mathrm{~cm}^{-1}$ are ascribed to the stretching vibrations of $\mathrm{C}-\mathrm{H}$ units (including $-\mathrm{CH}_{3}$ or $-\mathrm{CH}_{2} \mathrm{CH}_{3}$ ). The characteristic peaks at $1110 \mathrm{~cm}^{-1}$ and $827 \mathrm{~cm}^{-1}$ are due to the stretching modes and bending vibrations of $\mathrm{Si}-\mathrm{O}-$ $\mathrm{Si}^{32}$ respectively. The absorption by $\mathrm{O}-\mathrm{C}$ bonds occurs at $1050 \mathrm{~cm}^{-1}$. The peaks at $1410 \mathrm{~cm}^{-1}, 881 \mathrm{~cm}^{-1}$ and $700 \mathrm{~cm}^{-1}$ belong to the stretching and in-plane shear vibrations of $\mathrm{B}-\mathrm{O}$ units. ${ }^{33}$ In the spectrum of DBS-LDH, the characteristic peak at $3490 \mathrm{~cm}^{-1}$ is assigned to the stretching vibrations of the $-\mathrm{OH}$ groups attached to $\mathrm{Al}$ and $\mathrm{Mg}$ ions in the layers. ${ }^{30}$ The sulfonate 


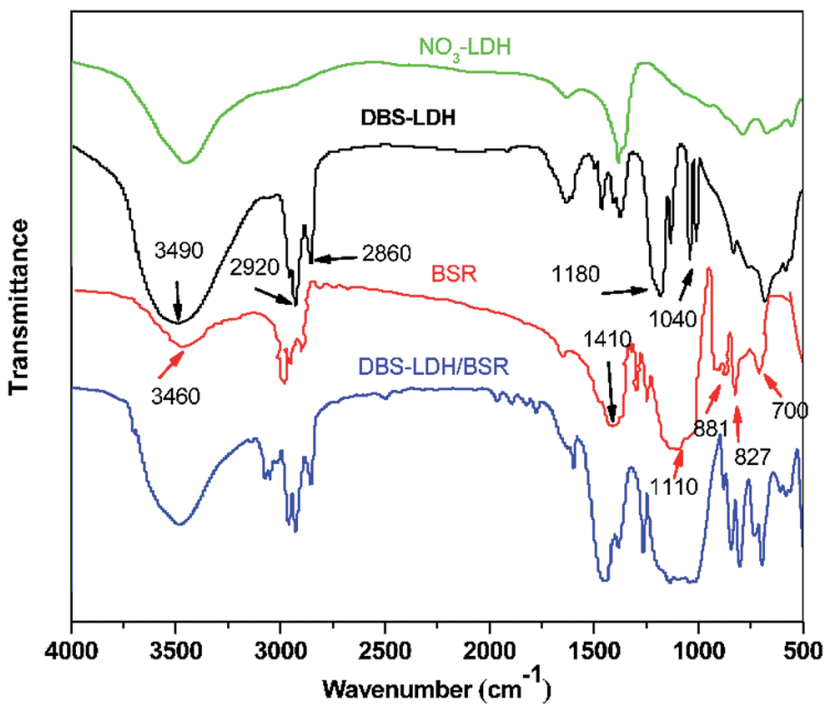

Fig. 1 FTIR spectra of DBS-LDH, BSR and DBS-LDH/BSR.

stretching bands occur at $1180 \mathrm{~cm}^{-1}$ and $1040 \mathrm{~cm}^{-1},{ }^{34}$ confirming the exchange of DBS ions in the interlayer space of LDH (consistent with the results of XRD), as shown in Scheme 1. In the spectrum of DBS-LDH/BSR, the peak at $3490 \mathrm{~cm}^{-1}(\mathrm{O}-\mathrm{H})$ is broader than that of DBS-LDH, indicating a slight reduction in the number of hydroxyl groups. This may be due to the dehydration of hydroxyls between DBS-LDH and BSR (in accordance with the results shown in Fig. 3). The broad band at 1250$1000 \mathrm{~cm}^{-1}$ is due to the overlap of $\mathrm{O}-\mathrm{C}, \mathrm{Si}-\mathrm{O}$ and sulfonate vibrations.

Fig. 2 shows the XPS wide-scan spectra of DBS-LDH/BSR. The peaks at $74 \mathrm{eV}, 1305 \mathrm{eV}, 532.5 \mathrm{eV}$ and $284.8 \mathrm{eV}$ are assigned to $\mathrm{Al}$ 2p, Mg 1s, O 1s and C 1s, respectively, ${ }^{35}$ verifying the presence of DBS-LDH in the hybrid composite. Furthermore, the peaks at binding energies of $101.23 \mathrm{eV}$ and $193.33 \mathrm{eV}$ are ascribed to Si $2 \mathrm{p}^{36}$ and $\mathrm{B} 1 \mathrm{~s}^{37,38}$, which further confirms that BSR has successfully combined with DBS-LDH.

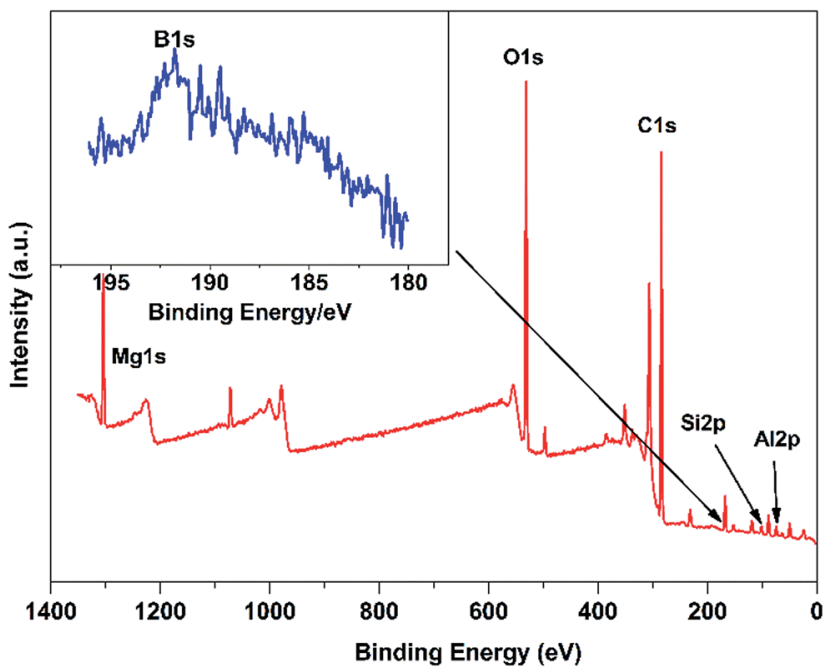

Fig. 2 XPS wide-scan spectra of DBS-LDH/BSR.

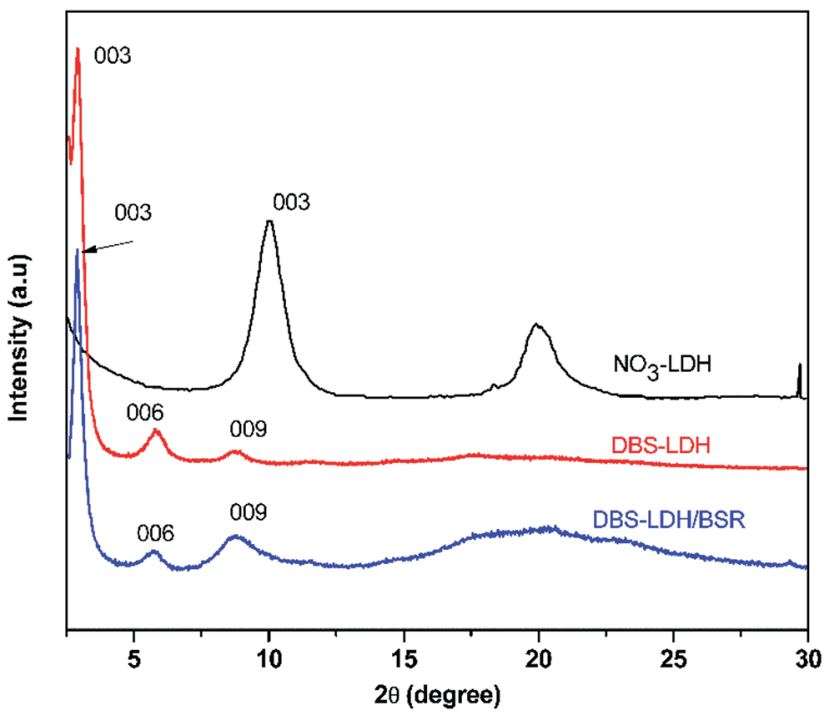

Fig. 3 XRD patterns of $\mathrm{NO}_{3}-\mathrm{LDH}, \mathrm{DBS}-\mathrm{LDH}$ and DBS-LDH/BSR.

Fig. 3 shows the XRD patterns of $\mathrm{NO}_{3}-\mathrm{LDH}$, DBS-LDH and DBS-LDH/BSR. The (003) reflection of $\mathrm{NO}_{3}-\mathrm{LDH}$ is located at $9.97^{\circ}$, giving a $d_{003}$ distance of $0.88 \mathrm{~nm}$. Following modification of $\mathrm{NO}_{3}$-LDH with SDBS, the (003) reflection shifts to a lower angle $\left(2.95^{\circ}\right)$. Thus, it can provide evidence for the intercalation of DBS ions into the interlayer galleries to increase the interlayer spacing $(2.9 \mathrm{~nm}){ }^{30,39}$ Furthermore, the dispersion of DBS-LDH in the polymer has greatly improved over that of the unmodified LDH. ${ }^{11}$ The thickness of $\mathrm{NO}_{3}$-LDH has been reported to be $0.48 \mathrm{~nm}$, and the distance between layers is $2.42 \mathrm{~nm}$, which is nearly identical to the length of the DBS molecular chain (approximately $2.1 \mathrm{~nm}$ ).$^{40}$ Therefore, we can conclude that DBS vertically intercalates into $\mathrm{NO}_{3}-\mathrm{LDH}$ (Scheme 1). As shown in Fig. 3, DBS-LDH/BSR exhibits the same diffraction peaks as DBS-LDH, showing that the distance between the layers of DBSLDH does not change upon combination with BSR. This result shows that the reaction between DBS-LDH and BSR occurs only on the surfaces of the DBS-LDH nanocrystals and does not change the bulk properties of DBS-LDH.

Panels a, b and c in Fig. 4 display the SEM images of $\mathrm{NO}_{3}$-LDH, DBS-LDH and DBS-LDH/BSR. As can be seen from the images, all exhibit lamellar plates. Compared with $\mathrm{NO}_{3}-\mathrm{LDH}$ and DBS-LDH, the layer structure of DBS-LDH/BSR is destroyed to some extent, which is due to the BSR grafting onto the surface of DBS-LDH.

\subsection{Thermal properties}

3.2.1 Thermal stability of flame retardants. The TGA thermograms of DBS-LDH, BSR and the DBS-LDH/BSR nanocomposites along with their derivative thermogravimetry (DTG) curves in air (a) and nitrogen (b) are presented in Fig. 5. In air, DBS-LDH displays a two-step thermogravimetric profile corresponding to physiosorbed and chemisorbed water (before 214.8 ${ }^{\circ} \mathrm{C}$ ) and the water arising from dehydroxylation of the layers $\left(300-587^{\circ} \mathrm{C}\right)$. DBS-LDH usually increases the thermal stability 

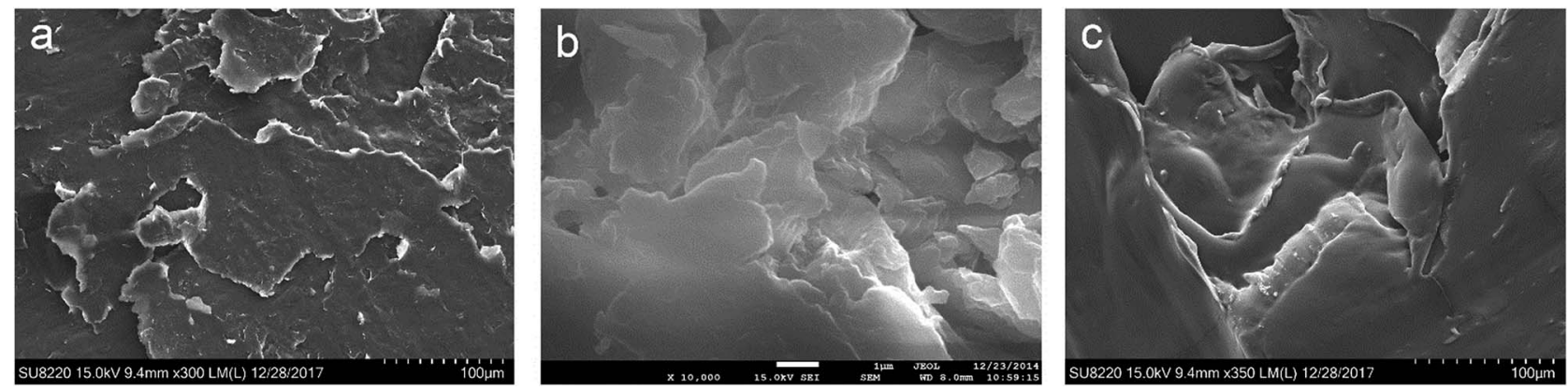

Fig. 4 SEM images of $\mathrm{NO}_{3}-\mathrm{LDH}, \mathrm{DBS}-\mathrm{LDH}$ and DBS-LDH/BSR.
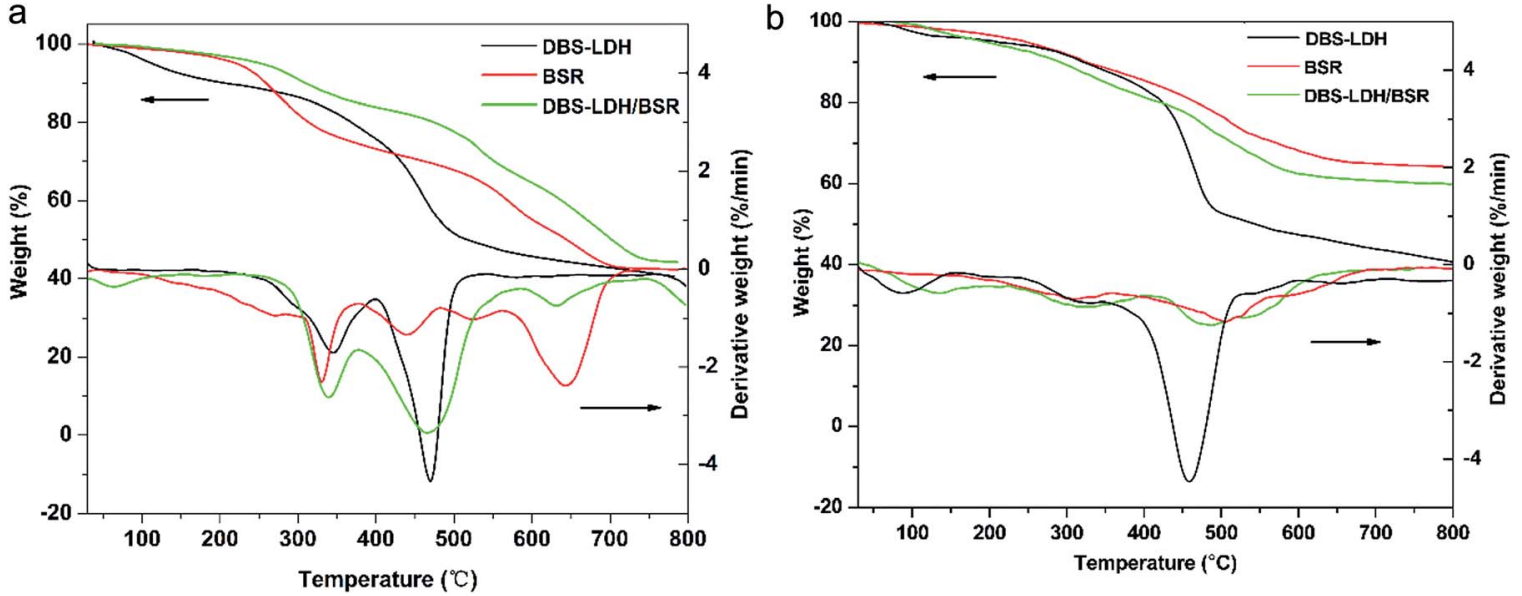

Fig. 5 TG/DTG profiles for the flame retardants under (a) air atmosphere and (b) nitrogen with $10{ }^{\circ} \mathrm{C} \mathrm{min}{ }^{-1}$ heating rate, $40 \mathrm{ml} \mathrm{min}{ }^{-1}$ gas flow rate and temperature range of $30-800{ }^{\circ} \mathrm{C}$.

of a polymer through its function as a physical barrier. It can hinder the diffusion of the degradation products, gases and heat. ${ }^{16,39} \mathrm{BSR}$ shows a slow rate of mass loss at $442{ }^{\circ} \mathrm{C}$, which is ascribed to the formation of $-\mathrm{Si}-\mathrm{O}-,-\mathrm{Si}-\mathrm{C}-$ and $-\mathrm{Si}-\mathrm{O}-\mathrm{B}-$ oxygen and heat-insulating layers. These layers can improve the thermal stability of the material and produce dense charring layers. The resulting DBS-LDH/BSR hybrid composite exhibits a thermogravimetric profile similar to that of DBS-LDH. The mass loss before $387^{\circ} \mathrm{C}$ is attributed to physiosorbed and chemisorbed water. The maximum mass loss rate is substantially lower (approximately 1.62\%) than that of BSR at $600-$ $700{ }^{\circ} \mathrm{C}$. Furthermore, the residual percentage of the DBS-LDH/ BSR composite is higher than those of DBS-LDH and BSR, indicating that the combination of DBS-LDH with BSR significantly improves the thermal oxidative resistance. In nitrogen, DBS-LDH starts to lose weight below $200{ }^{\circ} \mathrm{C}$, and the char residues at $800{ }^{\circ} \mathrm{C}$ are approximately $40 \%$. BSR and DBS-LDH/ BSR undergo similar degradation, which may be due to the stable BSR. The mass loss of DBS-LDH/BSR at temperatures below $200{ }^{\circ} \mathrm{C}$ is attributed to the degradation of BSR on the surface of DBS-LDH. Moreover, BSR exhibits higher char residue (65\%) than DBS-LDH/BSR (60\%). These results indicate that the BSR promotes char formation, which prevents the further oxidation and degradation of DBS-LDH/BSR.
3.2.2 Thermal stability of pure $\mathrm{PC}$ and its composites. Based on the TGA and DTG curves of PC and its composites (Fig. 6), the initial degradation temperature $\left(T_{5 \%}\right)$ is defined as the temperature at which the weight loss is $5 \mathrm{wt} \%$, where $T_{\max 1}$ and $T_{\max 2}$ represent the temperatures at which the first and second maximum mass loss rates occur, respectively. The values of these three parameters in addition to the char yield at $750{ }^{\circ} \mathrm{C}$ are recorded in Table 2. Under nitrogen atmosphere (Fig. 6(b)), pure PC and its composites show a one-stage degradation. This stage of weight loss arises from the decomposition of flame retardants and decomposition of the PC matrix. Table 2 shows that PC with DBS-LDH5/BSR5 has a better thermal stability. The $T_{5 \%}, T_{\max 1}$ and $T_{\max 2}$ values are much higher than pure PC and other PC composites. In air atmosphere (Fig. 6(a)), pure PC and its composites show two stages of weight loss. DBS-LDH/BSR clearly has a substantial effect on the thermal degradation of PC. The mass loss of PC begins at $324.1{ }^{\circ} \mathrm{C}$ in the first stage, and approximately $69 \mathrm{wt} \%$ of the mass is lost before $375^{\circ} \mathrm{C}$. In the second degradation region of $380-572{ }^{\circ} \mathrm{C}$, the degradation of both small molecules and linear molecules occurs. The degradation mechanism of PC in air was investigated by Jang et $a l .{ }^{41}$ The final residual amount of PC is $0.2 \mathrm{wt} \%$. Incorporating DBS-LDH into PC lowers the $T_{5 \%}$ value $\left(321.9^{\circ} \mathrm{C}\right)$ to below that of neat PC because of the presence of 

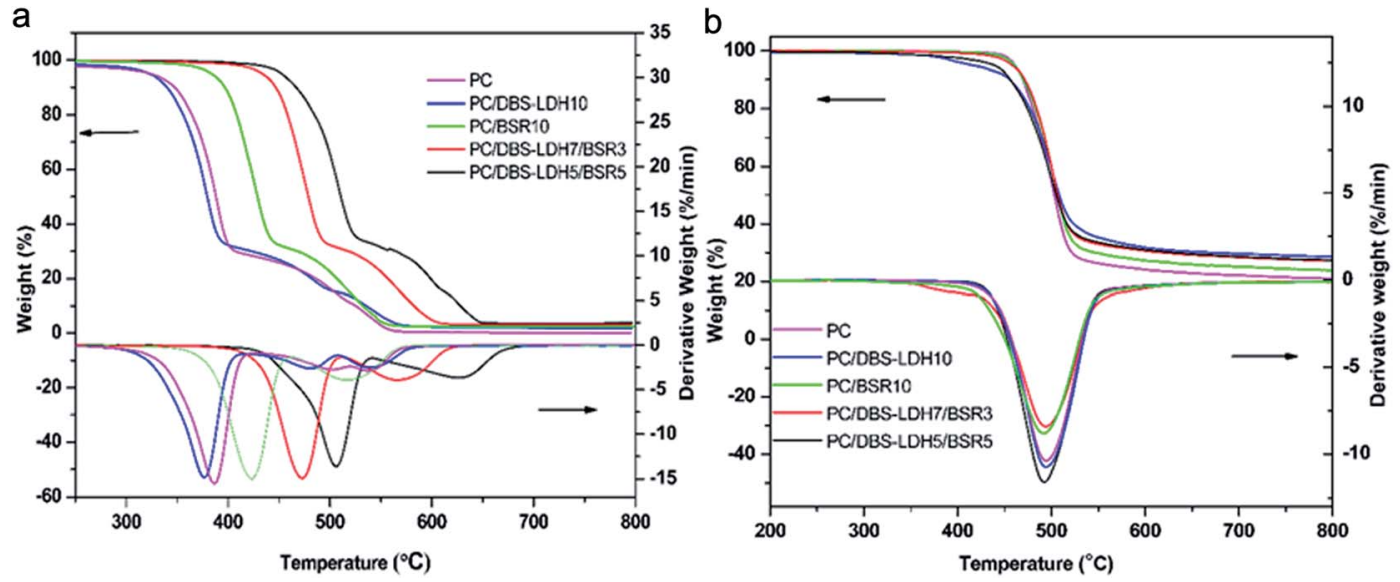

Fig. 6 TG/DTG curves of the different filler loadings of the PC composites under (a) air and (b) nitrogen atmosphere with $10{ }^{\circ} \mathrm{C}$ min ${ }^{-1}$ heating

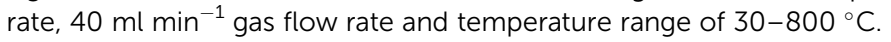

Table 2 Thermal analysis data of PC and its composites

\begin{tabular}{|c|c|c|c|c|c|c|c|c|}
\hline Sample & \multicolumn{2}{|c|}{$T_{5 \%}\left({ }^{\circ} \mathrm{C}\right)$} & \multicolumn{2}{|c|}{$T_{\max 1}\left({ }^{\circ} \mathrm{C}\right)$} & \multicolumn{2}{|c|}{$T_{\max 2}\left({ }^{\circ} \mathrm{C}\right)$} & \multicolumn{2}{|c|}{ Char yield at $750{ }^{\circ} \mathrm{C}$} \\
\hline PC/DBS-LDH10 & 322 & 408 & 374 & 493 & 479 & - & $1.80 \%$ & $28.90 \%$ \\
\hline PC/BSR10 & 386 & 457 & 422 & 494 & 521 & - & $2.58 \%$ & $24.00 \%$ \\
\hline PC/DBS-LDH7/BSR3 & 432 & 453 & 474 & 492 & 568 & - & $3.20 \%$ & $27.20 \%$ \\
\hline
\end{tabular}

unstable organic intercalation anions in $\mathrm{LDH}^{11}$ However, introducing the DBS-LDH/BSR hybrids, the $T_{5 \%}$ value is much higher than that of pure PC (Table 2). After the addition of $10 \mathrm{wt} \% \mathrm{BSR}, T_{5 \%}$ is $386{ }^{\circ} \mathrm{C}$, and the $T_{\max 1}, T_{\max 2}$ and the char residue at $750{ }^{\circ} \mathrm{C}$ also has improved comparing with pure PC. This result is attributed to the char formation of BSR after combustion. When 10 wt $\%$ DBS-LDH is introduced, $T_{5 \%}$ decreases by $2.2{ }^{\circ} \mathrm{C}$, and $T_{\max 1}$ and $T_{\max 2}$ also decrease by $13.8^{\circ} \mathrm{C}$ and $14{ }^{\circ} \mathrm{C}$, respectively. These small changes are caused by the unstable modifier (DBS) of $\mathrm{LDH}$. The char residue yield at $750{ }^{\circ} \mathrm{C}$ is $1.8 \mathrm{wt} \%$, which results from the char formation to protect PC from further burning. However, with the addition of $10 \mathrm{wt} \%$ BSR in PC, $T_{5 \%}$ increases to $386^{\circ} \mathrm{C}$, and $T_{\max 1}, T_{\max 2}$ and char residue at $750{ }^{\circ} \mathrm{C}$ improve observably comparing with pure PC. The promotion of heat-resistant performance of PC reveals that BSR disperses evenly in PC. The increased char residue is attributed to the formation of $\mathrm{SiO}_{2}$ or $\mathrm{B}_{2} \mathrm{O}_{3}$ (ref. 42) char from BSR after combustion. As shown in Table 2, the thermal stability is markedly enhanced by the incorporation of $10 \mathrm{wt} \%$ DBSLDH5/BSR5. Firstly, $T_{5 \%}$ increases to $452.4{ }^{\circ} \mathrm{C}$, which is approximately $128.3{ }^{\circ} \mathrm{C}$ higher than that of pure PC. Secondly, $T_{\max 1}$ and $T_{\max 2}$ increase by $118.4^{\circ} \mathrm{C}$ and $138.5^{\circ} \mathrm{C}$, respectively. At last, the final residue yield increases to $3.6 \mathrm{wt} \%$. This significant improvement in the thermal stability can be attributed to the synergistic effects of DBS-LDH and BSR, which functions as an effective barrier for inhibiting mass loss during the thermal degradation process.

\subsection{Mechanical properties}

Table 3 shows the mechanical properties of pure PC and its composites. As can be observed, the neat PC exhibits higher breaking elongation (4.49\%), ultimate tensile strength (38.743 $\mathrm{MPa})$, maximum strength $(140.370 \mathrm{kgf})$ and fracture strength $(3.866 \mathrm{MPa})$ comparing with its composites. In general, the flame-retardant fillers can lead to the reduction of mechanical properties of PC, which is mainly because of not much better additive-matrix compatibility. Even though the BSR is an organic flame retardant, its structure that includes stiff benzene rings may also affect the mechanical properties of PC. Additionally, the DBS-LDH is likely to form agglomerates, resulting in poorer interfacial interactions. Therefore, to obtain flame-retardant PC while to retain the mechanical properties, proper loadings of DBS-LDH and BSR seem to be essential.

\subsection{Flame retardant properties}

The flame retardancy of PC and its composites is evaluated by the LOI and UL-94 test (Fig. 7). Pure PC has a low LOI value of $26 \%$ and a V-2 rating in the UL-94 vertical burning test. Upon adding $10 \mathrm{wt} \%$ DBS-LDH, the LOI value increases to $29 \%$, and the material obtains a $\mathrm{V}-1$ rating. With the incorporation of $10 \mathrm{wt} \% \mathrm{BSR}$, the LOI reaches $28 \%$, and the UL-94 has a V-1 rating. When BSR is introduced (DBS-LDH/BSR hybrid composites), the flame retardancy of the PC composites further improves over that of pure PC. The LOI value increases to $34 \%$, 
Table 3 Mechanical properties of pure PC and its composites

\begin{tabular}{lllrl}
\hline Sample & $\begin{array}{l}\text { Breaking elongation } \\
(\%)\end{array}$ & $\begin{array}{l}\text { Ultimate tensile } \\
\text { strength (MPa) }\end{array}$ & $\begin{array}{l}\text { Maximum strength } \\
(\text { kgf })\end{array}$ & $\begin{array}{l}\text { Fracture strength } \\
(\mathrm{MPa})\end{array}$ \\
\hline PC & 4.490 & 38.743 & 140.370 & 3.866 \\
PC/DBS-LDH10 & 2.851 & 22.088 & 80.028 & 2.156 \\
PC/BSR10 & 3.379 & 28.222 & 102.250 & 2.762 \\
PC/DBS-LDH7/BSR3 & 3.038 & 22.392 & 81.127 & 2.238 \\
PC/DBS-LDH5/BSR5 & 4.148 & 25.716 & 93.172 & 2.564 \\
\end{tabular}

and a V-0 rating is obtained for PC/DBS-LDH5/BSR5. Thus, DBSLDH and BSR together enhance the fire retardancy. Pure PC exhibits obvious flame drips in the UL-94 vertical burning test (Fig. 8). The occurrence of flame drips decreases substantially, but not completely, when $10 \mathrm{wt} \%$ DBS-LDH is added to PC. After the incorporation of $10 \mathrm{wt} \% \mathrm{BSR}$, the flame drips still exist. In contrast, when both DBS-LDH and BSR are incorporated, the flame drips disappear completely. As for PC/DBS-LDH5/BSR5 composite, DBS-LDH acts as a barrier to maximize the heat insulation properties and minimize the permeability of volatile degradation products, while BSR promotes char formation during the burning process. Hence, the composite reduces the fire hazard during combustion, and the flame retardancy of PC improves greatly.

The morphologies of the char residues of the PC composites are further examined after the LOI tests by SEM. Fig. 9 shows the SEM photographs obtained for the exterior and interior of the chars from pure PC and a PC composite. The exterior char of pure PC consists of a porous residue, and its interior char shows much larger pores after combustion, indicative of the high flammability and poor thermostability of the pure PC char. In the case of the PC/DBS-LDH5/BSR5, the interior char shows smaller pores than those of the PC char and a continuous structure. Furthermore, the exterior char layer also shows a compact structure with small pores. The char layer protects PC from the radiant heat and direct contact with the flame,



Fig. 7 LOI values and UL-94 results of PC and its composites. effectively insulating the interior from gas and heat transfer. Therefore, the char layer plays an important role in improving the flame retardancy of PC.

Fig. 10 shows the heat release rate (HRR) versus time curves of pure PC and its composites. The peak heat release rate (PHRR) decreases from $294 \mathrm{~kW} \mathrm{~m}^{-2}$ for pure PC to $239 \mathrm{~kW} \mathrm{~m}^{-2}$



Fig. 8 Digital photos of the char residues of the PC composites containing different amounts of flame retardants (a) PC, (b) PC/DBSLDH10, (c) PC/BSR10, (d) PC/DBS-LDH7/BSR3 and (e) PC/DBS-LDH5/ BSR5.

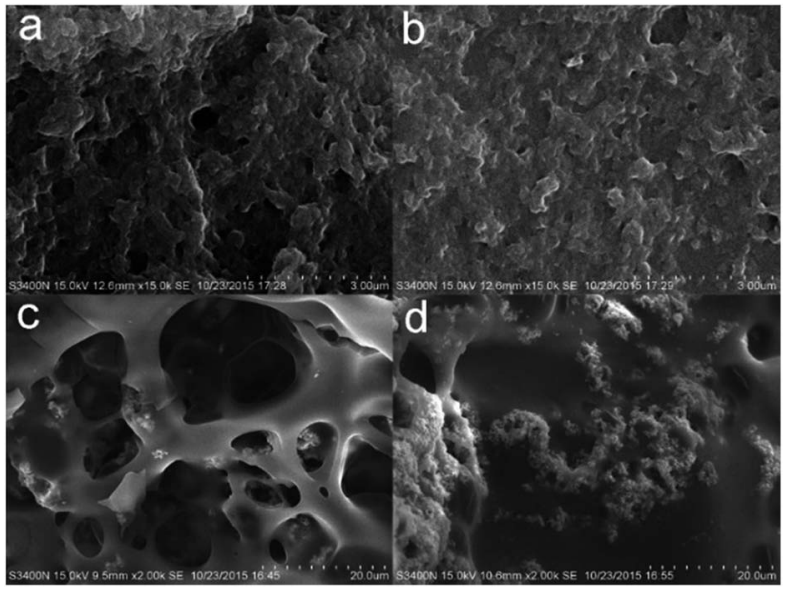

Fig. 9 SEM images of the exterior char residues of (a) $P C$ and (b) PC/ DBS-LDH5/BSR5 and the interior residual chars of (c) PC and (d) PC/ DBS-LDH5/BSR5. 


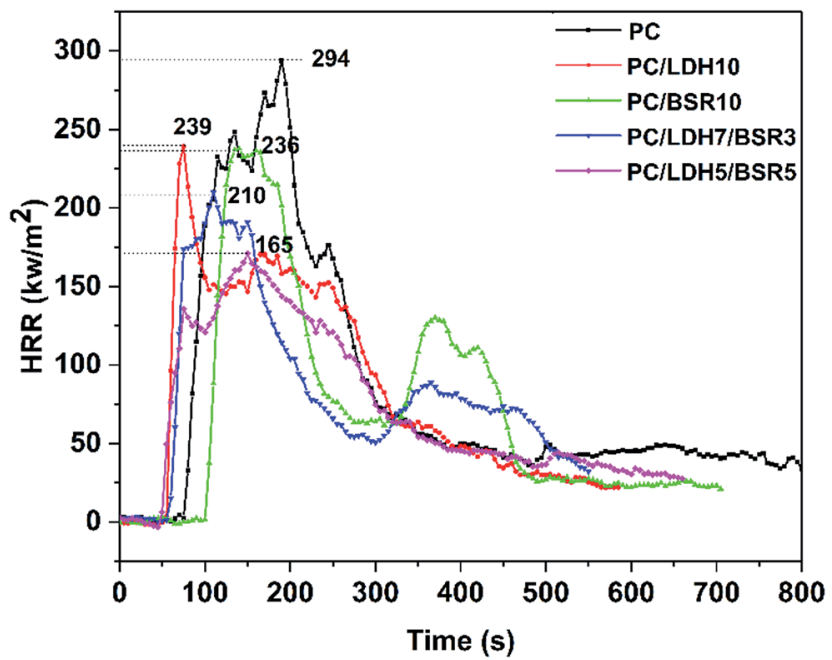

Fig. 10 HRR versus time curves of PC and its composites determined from cone calorimeter tests.

(-19\%), $236 \mathrm{~kW} \mathrm{~m}^{-2}(-19.7 \%), 210 \mathrm{~kW} \mathrm{~m}^{-2}(-29 \%)$ and $165 \mathrm{~kW} \mathrm{~m}^{-2}(-44 \%)$ for PC/DBS-LDH10, PC/BSR10, PC/DBSLDH7/BSR3 and PC/DBS-LDH5/BSR5, respectively. For pure PC, the PHRR occurs at approximately $190 \mathrm{~s}$, whereas those of PC/DBS-LDH10, PC/BSR10, PC/DBS-LDH7/BSR3 and PC/DBSLDH5/BSR5 appear at $71 \mathrm{~s}, 136 \mathrm{~s}, 110 \mathrm{~s}$ and $149 \mathrm{~s}$, respectively. For PC/BSR10, the PHRR decreases comparing with pure $\mathrm{PC}$, which is attributed to the BSR forming char residue to protect the PC composite. The PHRR reaches earlier in the PC composites (except for PC/BSR10) than in pure PC due to the intercalation of the unstable DBS in LDH. However, the PHRR decreases dramatically upon introducing DBS-LDH and DBSLDH/BSR into the PC. Specifically, the PC/DBS-LDH5/BSR5 composite shows a much better flame retardancy than all the other samples. As demonstrated by the first stage of the TGA curve obtained for the PC composites, the presence of DBSLDH/BSR contributes to charring. The char residues, which can prevent heat transfer and flame spread during combustion, are very important for the flame retardancy of the PC composites. Due to the synergistic effects of DBS-LDH and BSR, the char yields of the PC composites after burning increase (Table 2), which can remarkably enhance flame retardancy of PC composites.

\section{Conclusion}

In this study, the flame retardancy of PC has dramatically improved through the synergistic effects of DBS-LDH and BSR. The results show that DBS-LDH/BSR improves the thermal stability of PC and that the TGA char yield of PC/DBS-LDH5/ BSR5 at $800{ }^{\circ} \mathrm{C}$ increases to $3.75 \mathrm{wt} \%$ due to the synergistic effects of DBS-LDH and BSR. The results of the UL-94 vertical burning tests and the LOI tests reveal excellent flame retardancy following the addition of DBS-LDH5/BSR5 to PC. The LOI value increases to $34 \%$, and this formulation passes the UL-94 test with a V-0 rating. The improved fire safety of the composite is mainly due to the physical barrier created by the DBS-LDH/BSR, which prevents oxygen from penetrating into the material and confines heat transmission. In addition, the formation of a better char layer protects the PC composites from further burning, which reduces the fire hazard of PC. However, with the incorporation of DBS-LDH5/BSR5, mechanical properties of PC/ DBS-LDH5/BSR5 has decreased compared with pure PC. Therefore, it is a challenge for us to deal with.

\section{Conflicts of interest}

The author declares no conflict of interest.

\section{Acknowledgements}

This work was supported by the Applied Science and Technology Research and Development Special Foundation of Guangdong Province (Grant No.: 2016B090930004).

\section{References}

1 J. Wang, H. Li, G. Li, Z. Liu, Q. Zhang, N. Wang and X. Qu, J. Appl. Polym. Sci., 2017, 134, 44978.

2 S. Stassi, V. Cauda, C. Ottone, A. Chiodoni, C. F. Pirri and G. Canavese, Nano Energy, 2015, 13, 474-481.

3 W. Zhang, X. Li and R. Yang, Polym. Adv. Technol., 2012, 23, 588-595.

4 H. Cai, X. Zhang, K. Xu, H. Liu, J. Su, X. Liu, Z. Fu, Y. Guo and M. Chen, Polym. Adv. Technol., 2012, 23, 765-775.

5 I. Taraghi, A. Fereidoon, S. Paszkiewicz, A. Szymczyk, R. Chylinska, A. Kochmanska and Z. Roslaniec, Polym. Adv. Technol., 2017, 28, 1794-1803.

6 S.-Q. Fu, J.-W. Guo, D.-Y. Zhu, Z. Yang, C.-F. Yang, J.-X. Xian and X. Li, RSC Adv., 2015, 5, 67054-67065.

7 W. Yang, L. Song, Y. Hu, H. Lu and R. K. K. Yuen, Composites, Part B, 2011, 42, 1057-1065.

8 W. Zhang, G. Camino and R. Yang, Prog. Polym. Sci., 2017, 67, 77-125.

9 X. Chen, W. Wang, S. Li and C. Jiao, J. Hazard. Mater., 2017, 324, 789-796.

10 X. Chen, W. Wang and C. Jiao, J. Hazard. Mater., 2017, 331, 257-264.

11 N. J. Kang, D. Y. Wang, B. Kutlu, P. C. Zhao, A. Leuteritz, U. Wagenknecht and G. Heinrich, ACS Appl. Mater. Interfaces, 2013, 5, 8991-8997.

12 Z. Matusinovic and C. A. Wilkie, J. Mater. Chem., 2012, 22, 18701.

13 N. Nhlapo, T. Motumi, E. Landman, S. M. C. Verryn and W. W. Focke, J. Mater. Sci., 2007, 43, 1033-1043.

14 N. Iyi, Y. Ebina and T. Sasaki, J. Mater. Chem., 2011, 21, 8085. 15 G. R. Williams, N. H. Rees and D. O'Hare, Solid State Sci., 2009, 11, 1229-1238.

16 X. Wang, E. N. Kalali and D.-Y. Wang, ACS Sustainable Chem. Eng., 2015, 3, 3281-3290.

17 E. N. Kalali, X. Wang and D.-Y. Wang, J. Mater. Chem. A, 2016, 4, 2147-2157. 
18 Q. Wang, J. P. Undrell, Y. Gao, G. Cai, J.-C. Buffet, C. A. Wilkie and D. O'Hare, Macromolecules, 2013, 46, 6145-6150.

19 C. Zhao, G. Peng, B. Liu and Z. Jiang, J. Polym. Res., 2011, 18, 1971-1981.

20 D. Zhou, W. He, N. Wang, X. Chen, J. Guo and S. Ci, Polym. Compos., 2016, DOI: 10.1002/pc.24253.

21 L. Wang, X. He, H. Lu, J. Feng, X. Xie, S. Su and C. A. Wilkie, Polym. Adv. Technol., 2011, 22, 1131-1138.

22 A. Edenharter, P. Feicht, B. Diar-Bakerly, G. Beyer and J. Breu, Polymer, 2016, 91, 41-49.

23 F. Luo, K. Wu, D. Li, J. Zheng, H. Guo, Q. Zhao and M. Lu, Polym. Compos., 2017, 38, 2762-2770.

24 D. J. McGoldrick, R. J. Letcher, E. Barresi, M. J. Keir, J. Small, M. G. Clark, E. Sverko and S. M. Backus, Environ. Pollut., 2014, 193, 254-261.

25 Y. Jiang, X. Li and R. Yang, J. Appl. Polym. Sci., 2012, 124, 4381-4388.

26 M. Doğan and E. Bayraml, Polym. Adv. Technol., 2011, 22, 1628-1632.

27 Q. Zhang, W. Zhang, J. Huang, Y. Lai, T. Xing, G. Chen, W. Jin, H. Liu and B. Sun, Mater. Des., 2015, 85, 796-799.

28 E. Mansour, J. Mol. Struct., 2012, 1014, 1-6.

29 K. Xie, A. Gao and Y. Zhang, Carbohydr. Polym., 2013, 98, 706-710.

30 Z. Hao, J. Zhang, Y. Wu, J. Yu and L. Yu, J. Appl. Polym. Sci., 2014, 131, DOI: 10.1002/APP.40934.
31 X. Wang, Y. Spörer, A. Leuteritz, I. Kuehnert, U. Wagenknecht, G. Heinrich and D.-Y. Wang, RSC Adv., 2015, 5, 78979-78985.

32 M. D. Yuniati, T. Hirajima, H. Miki and K. Sasaki, Mater. Trans., 2015, 56, 1733-1741.

33 M. Środa and C. Paluszkiewicz, J. Mol. Struct., 2007, 834-836, 302-307.

34 J. Stejskal, I. Sapurina, M. Trchová and E. N. Konyushenko, Macromolecules, 2008, 41, 3530-3536.

35 X. Yuan, Y. Wang, J. Wang, C. Zhou, Q. Tang and X. Rao, Chem. Eng. J., 2013, 221, 204-213.

36 Z. Jiang, S. Fang, C. Wang, H. Wang and C. Ji, Appl. Surf. Sci., 2016, 390, 993-1001.

37 X. Yang, J. Li, L. Xing, Y. Liao, M. Xu, Q. Huang and W. Li, Electrochim. Acta, 2017, 227, 24-32.

38 S. Wang, X. Wang, B. Jia and X. Jing, Appl. Surf. Sci., 2017, 392, 481-491.

39 M. Shabanian, N. Basaki, H. A. Khonakdar, S. H. Jafari, K. Hedayati and U. Wagenknecht, Appl. Clay Sci., 2014, 90, 101-108.

40 G. H. Lu, M. He, H. Lu, X. L. Xie and L. J. Wang, Mater. Rev. B: Res., 2015, 29, 62-67.

41 B. N. Jang and C. A. Wilkie, Thermochim. Acta, 2005, 426, 7384.

42 P. Deng, Y. Shi, Y. Liu, Y. Liu and Q. Wang, Appl. Surf. Sci., 2018, 427, 894-904. 